\title{
The Impact of the COVID-19 Pandemic on the Perception of Health and Treatment-Related Issues among Patients with Phenylketonuria in Poland-The Results of a National Online Survey
}

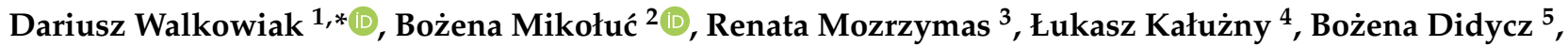 \\ Dorota Korycińska-Chaaban ${ }^{6}$, Michał Patalan ${ }^{7}$ (D), Joanna Jagłowska ${ }^{8}$, Agnieszka Chrobot ${ }^{9}$, Ewa Starostecka ${ }^{10}$, \\ Joanna Zarębska ${ }^{11}$ and Jarosław Walkowiak ${ }^{4}$ (D)
}

1 Department of Organization and Management in Health Care, Poznan University of Medical Sciences, Przybyszewskiego 39, 60-356 Poznan, Poland

2 Department of Pediatrics, Rheumatology, Immunology and Metabolic Bone Diseases, Medical University of Bialystok, 15-274 Bialystok, Poland; bozenam@mp.pl

3 Research and Development Center, Regional Specialist Hospital, 51-124 Wrocław, Poland; renata.mozrzymas@gmail.com

4 Department of Pediatric Gastroenterology and Metabolic Diseases, Poznan University of Medical Sciences, 61-701 Poznan, Poland; lukasz@jerozolima.poznan.pl (Ł.K.); jarwalk@ump.edu.pl (J.W.)

check for updates

Citation: Walkowiak, D.; Mikołuć, B. Mozrzymas, R.; Kałużny, Ł.; Didycz, B.; Korycińska-Chaaban, D.; Patalan, M.; Jagłowska, J.; Chrobot, A.; Starostecka, E.; et al. The Impact of the COVID-19 Pandemic on the Perception of Health and

Treatment-Related Issues among Patients with Phenylketonuria in Poland-The Results of a National Online Survey. Int. J. Environ. Res. Public Health 2021, 18, 6399. https:// doi.org/10.3390/ijerph18126399

Academic Editor: Francesco Corica

Received: 29 March 2021

Accepted: 10 June 2021

Published: 13 June 2021

Publisher's Note: MDPI stays neutral with regard to jurisdictional claims in published maps and institutional affiliations.

Copyright: (c) 2021 by the authors. Licensee MDPI, Basel, Switzerland. This article is an open access article distributed under the terms and conditions of the Creative Commons Attribution (CC BY) license (https:/ / creativecommons.org/licenses/by/ $4.0 /)$
5 Outpatient Metabolic Clinic, University Children's Hospital, 30-663 Krakow, Poland; bozenadidycz@wp.pl

6 PKU Polyclinic, Institute of Mother and Child, 01-211 Warsaw, Poland; chaaban@wp.pl

7 Department of Pediatrics, Endocrinology, Diabetology, Metabolic Diseases and Cardiology, Pomeranian Medical University, 70-204 Szczecin, Poland; mpatalan@hotmail.com

8 Department of Pediatrics, Hematology and Oncology, Medical University of Gdansk, 80-210 Gdansk, Poland; chabros_joanna@hotmail.com

9 Voivodship Children Hospital, 85-667 Bydgoszcz, Poland; aga.chrobot@wp.pl

10 The Regional Center of Rare Diseases, Polish Mother's Memorial Hospital Research Institute, 93-338 Lodz, Poland; ewastarostecka@wp.pl

11 Upper Silesian Child Health Centre, 40-752 Katowice, Poland; joanna.zarebska@gmail.com

* Correspondence: dariuszwalkowiak@ump.edu.pl; Tel./Fax: +48-61-658-44-93

Abstract: There is agreement that the pandemic has affected the healthcare system and behaviour of patients. This study aims to identify problems encountered by patients with phenylketonuria (PKU) and their parents/caregivers during the six-week pandemic lockdown in Poland (15 March to 30 April 2020). To determine the factors that influenced health and treatment-related issues, as well as the respondents' perception of the impact of the pandemic, study participants were asked to complete a non-validated online questionnaire comprising 31 questions (including 27 single-choice, two multiplechoice and two open-ended ones). A total of 571 patients or their parents completed the questionnaire, with $9.5 \%$ of respondents not performing any blood phenylalanine (Phe) test in the analysed period, $21.3 \%$ declaring a blood Phe increase, and $15.3 \%$ a decrease. Increased problems in contacting the doctor or dietitian were reported by $26.1 \%$ of subjects, whereas $39.3 \%$ of them felt restricted access to dietary products. Most (63.4\%) participants were satisfied with remote contact with their PKU clinic. Better compliance was associated with higher odds of acceptance of remote contact and of reporting fewer problems with contacting the doctor, and with lower odds of missing Phe testing. Self-reported high stress was associated with higher odds of reporting the limited availability of low-Phe products and Phe-free formulas, as well as with increased Phe concentrations and nonPKU-related health problems. These patients also had poor dietary compliance and experienced more problems in contacting specialists. Health and treatment-related problems experienced during the pandemic lockdown were related to a higher intensity of stress in patient's family and worse therapy compliance before the pandemic. Previous experience of remote visits resulted in a better perception of this method of contact. It seems that this form of communication should be popularized and improved to increase therapy effectiveness in case of different limitations in the future. Special attention should be paid to vulnerable patients who may be at extra risk when the provision of standard care is affected. 
Keywords: phenylketonuria; PKU; COVID-19 pandemic; compliance; remote medicine

\section{Introduction}

When diagnosed by newborn screening and treated immediately, patients with phenylketonuria (PKU; OMIM 261600) essentially show normal development, although neuropsychological deficits and behavioral, emotional and social issues have been reported [1-3]. The social burden associated with having a chronic disorder and strict dietary treatment, especially for patients with severe forms of PKU, could affect their healthrelated quality of life (HrQoL) [4]. Cotugno et al. [5] found lower HrQoL for children and adolescents with PKU, while Landolt et al. [6] reported impaired positive emotional functioning in a group of PKU children and adolescents. Bilder et al. [4] also showed that rates of autism spectrum disorders and eating disorders are significantly higher in the adult PKU population compared to the general population, similarly for rates of depression and anxiety in the overall PKU population [7,8]. Jahja et al. [9] reported that adolescent and adult PKU patients demonstrated poorer social cognition and had poorer social skills than controls, with a tendency towards lower or delayed autonomy [10] and emotional difficulties related to maintaining a PKU diet [11]. Moreover, patients often feel social isolation and limits on socialisation [12], with many of them identified as having significant neurocognitive, mental health and general health problems $[7,10,13,14]$. An association between parent stress, anxiety, and depression in parents of PKU children has also been described [12,15-18]. Therefore, any additional external factor might aggravate the observed problems.

The coronavirus disease 2019 (COVID-19) pandemic has changed the management of many chronic diseases, including inborn errors of metabolism such as PKU. The first case of severe acute respiratory syndrome coronavirus 2 (SARS-CoV-2) infection in Poland was confirmed on 4 March 2020, after which the Polish government imposed various types of lockdown control measures, with all schools (including universities) across the country suspended; shortly afterwards, distance teaching began. In the meantime, companies and institutions limited their activities, often asking their employees to work from home and many layoffs began. During the first six-week pandemic lockdown in Poland (15 March to 30 April 2020), the situation in the health care system also changed. All scheduled appointments were cancelled. The patients were instructed to contact their doctors and other team members by phone or e-mail when needed. However, PKU laboratories were working in a routine way.

Although Poland was not affected by the first wave of COVID-19 pandemic to the same extent as other European countries, the measures taken by the Polish government to restrain the spread of COVID-19 could have had a significant impact on patients with PKU and their families. Apart from the circumstances related to the need to maintain the continuity of care for patients with PKU, a new, unrecognised factor appeared in connection with the pandemic: social isolation, that is, the inability to leave home and contact a doctor in person, as well as potential restrictions on the sale of various products, including food and medications. Therefore, the question arose of how these external circumstances related to the pandemic have affected the PKU treatment process and life of PKU patients in general.

The present study aimed to identify problems encountered by PKU patients and parents/caregivers during the six-week pandemic lockdown and determine the factors that influenced health and treatment-related issues in this group of patients.

\section{Materials and Methods}

The study was planned for all patients with PKU, regardless of age, under the care of one of the 10 specialist centres treating PKU patients in Poland. The inclusion criteria comprised: a diagnosis of PKU, implementation of dietary recommendations since the 
diagnosis, and systematic care in the metabolic clinic, including blood collection according to their age. All patients had full access to Phe-free formulas and special low-protein products that are covered by health insurance.

Invitations to participate in an online (Microsoft Forms), anonymous study were distributed to PKU patients and their caregivers by e-mails, text messages, during planned contact with PKU specialists, or by phone. Additionally, we asked for information about the survey to be placed on the websites of local PKU communities. To the best of our knowledge, information about the survey was also distributed by the patients on social networks and by phone. Patients over 16 years of age were asked to complete the survey by themselves, and for the younger ones, parents/caregivers were invited to do so. However, the parents/caregivers could fill out the survey for all ages. The data were collected between 15 June and 20 July 2020.

The questionnaire was designed by the research PKU team in cooperation with a specialist in public health. This non-validated questionnaire comprised 31 questions, including 27 single-choice, two multiple-choice and two open-ended questions. All questions concerned pandemic-related events and circumstances which, in our opinion, could have had a direct or indirect impact on health and treatment-related issues in patients with PKU. We also aimed to capture the patients' perception of the impact of the pandemic. The questionnaire was designed using plain language and, wherever possible, specified response options using a five-point Likert scale graded from 1 (very dissatisfied/strongly disagree) to 5 (very satisfied/strongly agree) were used. The demographic part of the questionnaire consisted of questions about a patient's age, gender, information-where applicable-about who was filling in the questionnaire on behalf of the patient (parents, other caregivers), place of residence understood in terms of the distance from a specialist hospital, and time and method of travel to the hospital. Respondents were also asked about a possible COVID-19 diagnosis or quarantine, as well as how and how often they remotely (using any means of indirect contact, e.g., phone calls or text messages; video chat; e-mail, Messenger, Whatsapp or Facebook contact) communicated with their doctors and/or dietitians both before and during the pandemic. We investigated possible problems in contacting specialists and the frequency of this contact. We also asked about the Phe levels in the patient's blood before and during the pandemic and about problems maintaining their diet by the patients and in connection with possible problems with supply. Respondents were also asked about the perception of stress (on a scale graded from 1 to 10; 1 standing for low and 10 for high stress) they had experienced in connection with the pandemic. A series of questions concerned the assessment of remote contact with a specialist, the respondents' willingness to continue this type of contact in the future, and the possibility of remotely treating PKU and other diseases. We also inquired about leaving home during the lockdown, about the activities in connection with which the patient would go outside, as well as contact with other PKU patients. In two open-ended questions, patients/their caregivers were encouraged to share a detailed assessment of remote visits and the impact of the pandemic (inability to leave home, increased responsibilities) on diet compliance. The questionnaire was preceded by written information about the purpose and method of the study, the researchers conducting the study were mentioned by name, and an e-mail address of the coordinator was provided.

Since the questionnaire was by definition anonymous, we analysed the repetitiveness of responses and unusual response times. The answers to open-ended questions, which were meant to eliminate the use of bots, were also analysed. The respondents were asked to check whether any other family member took part in the survey earlier.

The data collected in the questionnaires were verified, checked for completeness, quality and consistency and exported into the statistical package JASP (Version 0.12.2) and STATISTICA v. 13.3 (TIBCO, Palo Alto, CA, USA). The results are presented as descriptive statistics (means and standard deviations (SDs), ranges and percentages). The odds ratio (OR) was calculated to compare patients according to different characteristics based on specific feelings, behaviour or opinions in relation to other groups of patients. A $95 \%$ 
confidence interval $(95 \% \mathrm{CI})$ was calculated to estimate the precision of the OR. The level of significance was set at $p<0.05$.

\section{Results}

Out of the 575 completed questionnaires, 571 were qualified for further analysis and four questionnaires were excluded since the respondents were younger than 16 . The mean age of the patients was 14.77 years (Table 1), with 296 (51.8\%) females and 275 (48.2\%) males. Almost three-quarters of the questionnaires were completed by the patients' parents or other caregivers. Prior to the pandemic, nearly two-thirds of patients reported blood Phe levels within the recommended target for age; more than half stated that their results had not changed during the pandemic, although according to over $20 \%$ of respondents, Phe blood test results worsened in this period.

Most $(53.4 \%)$ respondents declared that they used to contact their specialist doctor or dietitian by phone before the pandemic, whereas $10.1 \%$ contacted them using a video conference application or online messaging (Supplementary Table S1). During the pandemic, $58.3 \%$ of patients or their carers contacted their physician by phone, $20.0 \%$ by e-mail, and $13.5 \%$ by text message, with $31.9 \%$ of patients not feeling the need for such contact. A quarter $(26.1 \%)$ of patients believed that problems with contact with their doctor and nutritionist increased, whereas $43.8 \%$ thought that they decreased. The number of patient contacts with their doctors or dietitians in the first six weeks of the pandemic in Poland ranged from 0 to 12 .

Most (63.4\%) of the surveyed patients/carers were satisfied with remote contact with a doctor and a dietitian, while only $4.4 \%$ were not satisfied (Supplementary Table S2). More than half $(53.6 \%)$ of the respondents would like to use that form of contact in the future, while $19.0 \%$ of the respondents would not. Additionally, $40.8 \%$ of the respondents believed that in the case of PKU treatment, remote contact can replace direct contact with a specialist.

Limited access to special low-protein products and Phe-free formulas was reported by $39.3 \%$ and $20.7 \%$ of the respondents, respectively (Supplementary Table S3), with only $12.6 \%$ of patients considering that it was difficult to follow the diet in this period, whereas $42.2 \%$ were of the opposite opinion. Only $10.5 \%$ of patients during the pandemic spent time outdoors more often than before, in particular, for necessary housework, garden work and shopping. It should be noted, however, that as many as $24.0 \%$ of those surveyed reported practising sports in the period when it was prohibited.

According to the responses to the question "Did you use to contact your PKU specialist/dietitian by phone prior to the pandemic?" (Supplementary Table S1), the respondents were divided into three groups. The first group consisted of people who declared frequent telephone contact with their doctor (answer: regularly), the second group comprised those who declared that they contacted their doctor via telephone from time to time (answers: several times), and the remainder constituted the third group. The first and the second group were compared to the third group, calculating the OR of satisfaction with remote visits and willingness to use such contact in the future between groups. The ORs of being satisfied with remote contact with a PKU doctor for a person having regular/frequent contact in the past was higher than for those with no or occasional contact. Similarly, patients from the first and second groups were more interested in future remote contact (Table 2). 
Table 1. Respondents' characteristics $(\mathrm{N}=571)$.

\begin{tabular}{|c|c|}
\hline Characteristics & $\mathbf{n} / \mathbf{N}(\%)$ \\
\hline Number of patients & 571 \\
\hline \multicolumn{2}{|l|}{ Patient gender } \\
\hline Female & $296(51.8)$ \\
\hline Male & $275(48.2)$ \\
\hline Mean age (SD) & $14.77(12.6)$ \\
\hline Age range & $0.17-53$ \\
\hline Missing age data & $4(0.7)$ \\
\hline Number of patients $>26$ years under parents' supervision & $42(7.4)$ \\
\hline Questionnaire filled in by parents & $424(74.3)$ \\
\hline Questionnaire filled in by patients & $147(25.7)$ \\
\hline Quarantined & $11(1.9)$ \\
\hline \multicolumn{2}{|l|}{ Self-reported Phe levels before the pandemic } \\
\hline As recommended & $363(63.6)$ \\
\hline Slightly too high & $174(30.5)$ \\
\hline Far too high & $34(5.9)$ \\
\hline \multicolumn{2}{|l|}{ Self-reported Phe levels during the pandemic lockdown } \\
\hline Increased considerably & $27(4.7)$ \\
\hline Increased slightly & $95(16.6)$ \\
\hline Remained the same & $302(52.9)$ \\
\hline Decreased slightly & $75(13.1)$ \\
\hline Decreased considerably & $18(3.2)$ \\
\hline No tests in lockdown period & $54(9.5)$ \\
\hline \multicolumn{2}{|l|}{ Distance between household and the clinic } \\
\hline In our city & $102(17.9)$ \\
\hline Less than $50 \mathrm{~km}$ & $112(19.6)$ \\
\hline $50-100 \mathrm{~km}$ & $128(22.4)$ \\
\hline More than $100 \mathrm{~km}$ & $229(40.1)$ \\
\hline \multicolumn{2}{|l|}{ Mode of travel to clinic } \\
\hline Own car & $453(79.3)$ \\
\hline Rented car & $15(2.6)$ \\
\hline City transport & $45(7.9)$ \\
\hline Train or intercity bus & $45(7.9)$ \\
\hline Several trains or buses & $13(2.3)$ \\
\hline \multicolumn{2}{|l|}{ Travel time to doctor } \\
\hline Less than $0.5 \mathrm{~h}$ & $105(18.4)$ \\
\hline $0.5-1 \mathrm{~h}$ & $153(26.8)$ \\
\hline $1-2 \mathrm{~h}$ & $174(30.5)$ \\
\hline $2-3 \mathrm{~h}$ & $91(15.9)$ \\
\hline More than $3 \mathrm{~h}$ & $48(8.4)$ \\
\hline
\end{tabular}

$\mathrm{N}-$ number of all respondents, $\mathrm{n}-$ number of a given answer, SD—standard deviation, Phe - phenylalanine. 
Table 2. The impact of contact frequency with a doctor before the pandemic on satisfaction with remote visits.

\begin{tabular}{ccc}
\hline & \multicolumn{3}{c}{ Phone Contact Frequency } \\
\cline { 2 - 3 } & $\begin{array}{c}\text { Group 1 (Patients with Regular Phone } \\
\text { Contact with PKU Doctor/Dietitian } \\
\text { before Pandemic) vs. Group 3 (Patients } \\
\text { with Occasional/No Contact) }\end{array}$ & $\begin{array}{c}\text { Group 2 (Patients with Several Phone } \\
\text { Contacts with PKU Doctor/Dietitian } \\
\text { before Pandemic) vs. Group 3 (Patients } \\
\text { with Occasional/No Contact) }\end{array}$ \\
\hline WR & Were you satisfied with the remote contact? \\
$95 \%$ CI & 22.47 & 8.30 \\
$p$ & $12.57-40.14$ & $5.34-12.90$ \\
& $<0.0001$ & $<0.0001$ \\
\hline OR & Would you like to have remote contact in the future? \\
$95 \%$ CI & 2.35 & 1.98 \\
$p$ & $1.54-3.59$ & $1.34-2.93$ \\
& $<0.0001$ & 0.0003 \\
\hline
\end{tabular}

PKU—phenylketonuria, OR—odds ratio, CI—confidence interval.

The respondents' travel time to their doctor exceeding three hours was associated with a higher OR of their recognition of remote contact as a method of PKU treatment (Table 3).

Table 3. The impact of travel time for a medical visit before the pandemic on satisfaction with remote visits.

\begin{tabular}{ccc}
\hline & \multicolumn{2}{c}{ Travel Time to the Centre } \\
\cline { 2 - 3 } & \multicolumn{3}{c}{ How Long Does It Take to Get to Your Doctor? } \\
\cline { 2 - 3 } OR & $\mathbf{3}$ h to the Doctor vs. All Others & $>\mathbf{2} \mathbf{~ h ~ v s . ~}<\mathbf{1} \mathbf{~ h}$ \\
$95 \% \mathrm{CI}$ & 2.17 & 1.77 \\
$p$ & $1.19-3.96$ & $1.17-2.69$ \\
\hline OR一odds ratio & 0.0057 & 0.0037 \\
\hline
\end{tabular}

The patients' normal blood Phe level was associated with a higher OR of their satisfaction with remote contact as a method of PKU treatment (Table 4). The same patients had fewer problems contacting their doctor, lower odds of missing Phe testing and higher odds of being interested in future remote contact instead of in person.

Table 4. Self-reported Phe levels (normal vs. abnormal) before the pandemic and the perception of remote visits, availability of specialists and the lack of control Phe tests during the pandemic.

\begin{tabular}{ccccc}
\hline & \multicolumn{3}{c}{ Self-Reported Phe Levels (Normal vs. Abnormal) } \\
\cline { 2 - 5 } & $\begin{array}{c}\text { Satisfaction with } \\
\text { Remote Contact }\end{array}$ & $\begin{array}{c}\text { Problems in Contacting a } \\
\text { Specialist }\end{array}$ & $\begin{array}{c}\text { No Tests during the } \\
\text { Pandemic }\end{array}$ & $\begin{array}{c}\text { Positive Opinion on Remote Contact } \\
\text { as a Means of Treating PKU }\end{array}$ \\
\hline OR & 1.56 & 0.59 & 0.42 & 1.68 \\
$95 \%$ CI & $1.10-2.22$ & $0.40-0.87$ & $0.24-0.76$ & $1.10-2.56$ \\
$p$ & 0.0063 & 0.0034 & 0.0020 & 0.0080 \\
\hline
\end{tabular}

PKU—phenylketonuria, OR—odds ratio, CI-confidence interval.

High stress intensity (from 7 to 10) was associated with higher OR of reporting limited low-Phe product availability and limited Phe-free formula availability than lower feelings of stress (from 1 to 6). These patients also had poor dietary compliance, experienced more problems in contacting specialists, and a higher need to contact other PKU patients/parents. 
Self-reported high stress intensity was associated with higher OR of an increase in Phe concentrations and non-PKU-related health problems (Table 5).

Table 5. Comparison of patients' frequency of reporting high stress vs. low-intermediate stress intensity depending on social interactions.

\begin{tabular}{|c|c|c|c|c|c|}
\hline & \multicolumn{5}{|c|}{ Social Interactions (Declarations) } \\
\hline & $\begin{array}{l}\text { Limited Low-Phe } \\
\text { Product Availability }\end{array}$ & $\begin{array}{l}\text { Limited Phe-Free } \\
\text { Formula Availability }\end{array}$ & $\begin{array}{l}\text { Worse Dietary } \\
\text { Compliance }\end{array}$ & $\begin{array}{l}\text { Need to Contact Other } \\
\text { Parents/Patients }\end{array}$ & $\begin{array}{c}\text { Problems in } \\
\text { Contacting a } \\
\text { Specialist }\end{array}$ \\
\hline OR & 2.00 & 1.87 & 2.03 & 1.97 & 1.55 \\
\hline $95 \% \mathrm{CI}$ & $1.42-2.84$ & $1.24-2.64$ & $1.24-3.35$ & $1.22-3.19$ & $1.06-0.27$ \\
\hline \multirow[t]{3}{*}{$p$} & $<0.0001$ & $<0.0001$ & $<0.0001$ & 0.0028 & 0.0016 \\
\hline & \multicolumn{5}{|c|}{ Social Interactions (Declaration/Report) } \\
\hline & \multicolumn{3}{|c|}{ an Increase of Phe Concentrations } & \multicolumn{2}{|c|}{ Other Than PKU-Related Health Problem } \\
\hline OR & \multicolumn{3}{|c|}{1.95} & \multicolumn{2}{|c|}{3.67} \\
\hline $95 \% \mathrm{CI}$ & \multicolumn{3}{|c|}{$1.23-3.10$} & \multicolumn{2}{|c|}{$1.75-7.69$} \\
\hline$p$ & \multicolumn{3}{|c|}{0.0023} & \multicolumn{2}{|c|}{0.0003} \\
\hline
\end{tabular}

Phe—phenylalanine, PKU—phenylketonuria, OR—odds ratio, CI—confidence interval.

\section{Discussion}

This study has identified health and treatment-related issues in PKU patients and their families resulting from the COVID-19 pandemic lockdown restrictions. The study findings are of important practical significance on many levels and in the short term may offer practical hints relevant in the case of another lockdown in the COVID-19 pandemic. Regarding the long-term perspective, our respondents' experience of contact with the healthcare professionals contributes to their opinion on the usefulness of telemedicine in the future, after the end of the pandemic. Additionally, the study findings concern patients and their families, specialist doctors and dietitians who support patients in their fight against the disease, and the health care system as such, including the organisation of treatment. It is anticipated that our results could help to prepare healthcare providers for similar future events, to change the healthcare system, and to more adequately meet patients' needs and expectations. Further actions would be crucial to sustain reasonable metabolic control as documented in the present study. To some degree, mental health problems in the population induced by the pandemic were predictable, as confirmed by the results of the latest mental health research [19-22]. There were also doubts about the health care system and its effectiveness in the face of information about new COVID-19 cases. Moreover, the changing situation could result in increased stress and non-compliance, with reduced physical activity causing a decrease in energy and macronutrient needs. Significant group of patients and their caregivers reported stress as an important problem, some of them also reporting shortages of low-Phe products. Moreover, even if the cause of anxiety or stress was not fully rational, this does not mean that stress did not affect the course of treatment. Nonetheless, various stress-related phenomena emerged in entire populations during the pandemic and the general atmosphere likely affected our respondents as well [23-26]. Our patients are routinely advised to follow an active lifestyle, and this recommendation could be of great importance, especially in terms of their psychological well-being.

The results of our study confirm previous findings regarding the need for psychological support to reduce levels of stress and anxiety during a pandemic for patients with rare diseases and their families, as well as for providing remote counselling to the extent that, due to the specificity of the disease, it is possible [27-29]. Similar to the findings concerning patients with cystic fibrosis (CF) [29], our patients also reported changes in daily routine during self-isolation; this was mostly unintentional non-adherence to treatment for $\mathrm{CF}$, whereas, in our study, most respondents' self-reported adherence was better, though some reported poor adherence or complete non-adherence to their diet. As it has been shown 
earlier [30], compliance deteriorates with the patient's age, though this study suggests that compliance may also be influenced by external factors. Regardless of the readiness of the healthcare system, the application of telemedicine in the new COVID-19 reality is unquestionable. Special emphasis should be put in the future on video consulting and everyone should contribute to the increase of its use. A wide-ranging information campaign regarding the possibility of remote visits to doctors of various specialties was launched in March 2020, with the pandemic accelerating the implementation and popularisation of remote visits among patients in different countries and suffering from different diseases [20,31-33]. The possibility of using remote visits in the treatment of rare diseases [34,35], paediatric treatment [36] or chronic diseases [37,38] had been discussed previously. The applicability of such treatment in patients with PKU has remained outside the mainstream, but the pandemic has shown that, to some extent, remote visits are possible.

Opinions on remote visits for patients with PKU and their parents are closely related to their previous experience with this form of treatment. Since many patients do not have such experience, opinions about the visits also varied. It seems that people in Poland do not need to be convinced to use video calls as a form of communication [39], but there is a need to enable them to use this tool, not only for private purposes but also for patient-doctor communication. This requires adjustments on the part of the health service, both in terms of the willingness of teams participating in the treatment of patients with PKU to engage in remote medicine but also in terms of changes in the infrastructure of the health care system. Future lockdowns being a possibility, there is no other option but to familiarise patients with remote visits, especially as they are likely to become the only possible type of contact soon. For patients who have doubts as to the effectiveness of remote treatment, the healthcare system should make the first move to initiate such visits.

There are some limitations to this study. Firstly, we used a non-validated questionnaire. Secondly, we referred to only a six-week lockdown. One could have expected more disparities if we had assessed a longer period with a possibly worse effect for the most vulnerable. The strength of the present study is its sample size, with a high response rate (definitely exceeding 50\%).

In summary, pandemic-related self-reported stress in many patients with PKU or/and their caregivers was very high and more frequently resulted in lower treatment compliance. These patients also more often reported problems contacting a specialist, which, taking into account their more frequent Phe results over the therapeutic range, may be an attempt at self-justification. It is necessary to quickly identify patients from that group and implement psychological support, as well as to try to reimplement the diet and compliance regime. One-third of patients did not have contact with a doctor or nutritionist during the pandemic, with 1 in 10 patients not performing blood tests during the lockdown and one in five patient's Phe results worsened. For at least $30 \%$ of patients, this urgently requires the restoration of the pre-pandemic metabolic control. The results of our study suggest a significant number of people experienced stress; however, considering the nature of the survey and the possible bias resulting from the fact that the group was not fully representative, the situation in the entire population of PKU patients may be even worse than our results indicate [40].

As we can see, our patients accept the solutions they are familiar with; a possibly long future period of non-existent or limited personal contact requires the preparation of patients for forms of therapy that enable supervision and support in maintaining metabolic control. Additionally, for patients with a long travel time to the hospital, it seems appropriate to consider maintaining remote visits to some extent even after the coronavirus threat is over, subsequently offering such an option to patients living closer to PKU treatment centres provided they can engage well in the methods used. The healthcare providers should define the most vulnerable patients at the highest risk of losing proper control. It is important when establishing remote clinics in the future to bear in mind that this may actually intensify social disparities. When choosing a treatment method, it is crucial 
to define individual needs rather than adopt the same approach for everyone. More vulnerable patients may need more face-to-face contact.

\section{Conclusions}

Health and treatment-related problems experienced during the pandemic lockdown were related to a higher intensity of stress in patients' families and worse therapy compliance before the pandemic. Previous experience of remote visits resulted in a better perception of this method of contact. The popularisation and improvement of this form of communication is warranted to increase the effectiveness of therapy in case of different limitations in the future, such as a new lockdown. It is also a promising attitude for future PKU treatment regardless of the pandemic, especially in patients experiencing problems with visiting a PKU centre.

Supplementary Materials: The following are available online at https:/ / www.mdpi.com/article/ 10.3390/ijerph18126399/s1, Table S1: Characteristics of contacts with a PKU specialist doctor and dietitian ( $\mathrm{N}=571)$, Table S2: Respondents' opinions on remote contact in the treatment of PKU $(\mathrm{N}=571)$, Table S3: Respondents' opinions on access to special food, diet, activities and stress during the pandemic $(\mathrm{N}=571)$.

Author Contributions: D.W., R.M., B.M. and J.W. participated in the original design of the study. D.W. supervised conceptualization of the study and the collection of data. All authors contributed to the acquisition of data. D.W. and J.W. performed the statistical analyses and wrote the original draft of the manuscript. All authors have read and agreed to the published version of the manuscript.

Funding: This research received no external funding.

Institutional Review Board Statement: The study was approved by the Bioethical Committee at the Medical University, Poznan, Poland (KB/406/20).

Informed Consent Statement: Patient consent was waived due to the voluntary character of participation in the study. The ethics committee approved this study.

Data Availability Statement: The datasets used and/or analyzed in the current study are available from the corresponding author on reasonable request.

Acknowledgments: We wish to thank all PKU patients and their parents/caregivers who participated by completing the questionnaire.

Conflicts of Interest: The authors have no conflicts of interest.

\section{Abbreviations}

PKU: phenylketonuria: Phe: phenylalanine, PAH: phenylalanine hydroxylase.

\section{References}

1. Ashe, K.; Kelso, W.; Farrand, S.; Panetta, J.; Fazio, T.; De Jong, G.; Walterfang, M. Psychiatric and Cognitive Aspects of Phenylketonuria: The Limitations of Diet and Promise of New Treatments. Front. Psychiatry 2019, 10, 561. [CrossRef]

2. Bosch, A.M.; Burlina, A.; Cunningham, A.; Bettiol, E.; Moreau-Stucker, F.; Koledova, E.; Benmedjahed, K.; Regnault, A. Assessment of the Impact of Phenylketonuria and Its Treatment on Quality of Life of Patients and Parents from Seven European Countries. Orphanet J. Rare Dis. 2015, 10, 80. [CrossRef]

3. Enns, G.M.; Koch, R.; Brumm, V.; Blakely, E.; Suter, R.; Jurecki, E. Suboptimal Outcomes in Patients with PKU Treated Early with Diet Alone: Revisiting the Evidence. Mol. Genet. Metab. 2010, 101, 99-109. [CrossRef]

4. Bilder, D.A.; Kobori, J.A.; Cohen-Pfeffer, J.L.; Johnson, E.M.; Jurecki, E.R.; Grant, M.L. Neuropsychiatric Comorbidities in Adults with Phenylketonuria: A Retrospective Cohort Study. Mol. Genet. Metab. 2017, 121, 1-8. [CrossRef] [PubMed]

5. Cotugno, G.; Nicolò, R.; Cappelletti, S.; Goffredo, B.M.; Dionisi Vici, C.; Di Ciommo, V. Adherence to Diet and Quality of Life in Patients with Phenylketonuria. Acta Paediatr. 2011, 100, 1144-1149. [CrossRef] [PubMed]

6. Landolt, M.A.; Nuoffer, J.-M.; Steinmann, B.; Superti-Furga, A. Quality of Life and Psychologic Adjustment in Children and Adolescents with Early Treated Phenylketonuria Can Be Normal. J. Pediatr. 2002, 140, 516-521. [CrossRef] [PubMed] 
7. Trefz, K.F.; Muntau, A.C.; Kohlscheen, K.M.; Altevers, J.; Jacob, C.; Braun, S.; Greiner, W.; Jha, A.; Jain, M.; Alvarez, I.; et al. Clinical Burden of Illness in Patients with Phenylketonuria (PKU) and Associated Comorbidities-a Retrospective Study of German Health Insurance Claims Data. Orphanet J. Rare Dis 2019, 14, 181. [CrossRef] [PubMed]

8. Pietz, J.; Fätkenheuer, B.; Burgard, P.; Armbruster, M.; Esser, G.; Schmidt, H. Psychiatric Disorders in Adult Patients with Early-Treated Phenylketonuria. Pediatrics 1997, 99, 345-350. [CrossRef]

9. Jahja, R.; van Spronsen, F.J.; de Sonneville, L.M.J.; van der Meere, J.J.; Bosch, A.M.; Hollak, C.E.M.; Rubio-Gozalbo, M.E.; Brouwers, M.C.G.J.; Hofstede, F.C.; de Vries, M.C.; et al. Social-Cognitive Functioning and Social Skills in Patients with Early Treated Phenylketonuria: A PKU-COBESO Study. J. Inherit. Metab. Dis. 2016, 39, 355-362. [CrossRef]

10. Burton, B.K.; Jones, K.B.; Cederbaum, S.; Rohr, F.; Waisbren, S.; Irwin, D.E.; Kim, G.; Lilienstein, J.; Alvarez, I.; Jurecki, E.; et al. Prevalence of Comorbid Conditions among Adult Patients Diagnosed with Phenylketonuria. Mol. Genet. Metab. 2018, 125, 228-234. [CrossRef]

11. Palermo, L.; MacDonald, A.; Limback, E.; Robertson, L.; Howe, S.; Geberhiwot, T.; Romani, C. Emotional Health in Early-Treated Adults with Phenylketonuria (PKU): Relationship with Cognitive Abilities and Blood Phenylalanine. J. Clin. Exp. Neuropsychol. 2020, 42, 142-159. [CrossRef]

12. Ford, S.; O'Driscoll, M.; MacDonald, A. Living with Phenylketonuria: Lessons from the PKU Community. Mol. Genet. Metab. Rep. 2018, 17, 57-63. [CrossRef] [PubMed]

13. Darbà, J. Characteristics, Comorbidities, and Use of Healthcare Resources of Patients with Phenylketonuria: A Population-Based Study. J. Med. Econ. 2019, 22, 1025-1029. [CrossRef] [PubMed]

14. Walkowiak, D.; Kaluzny, L.; Bukowska-Posadzy, A.; Oltarzewski, M.; Staszewski, R.; Moczko, J.A.; Musielak, M.; Walkowiak, J. Overweight in Classical Phenylketonuria Children: A Retrospective Cohort Study. Adv. Med. Sci. 2019, 64, 409-414. [CrossRef] [PubMed]

15. Carpenter, K.; Wittkowski, A.; Hare, D.J.; Medford, E.; Rust, S.; Jones, S.A.; Smith, D.M. Parenting a Child with Phenylketonuria (PKU): An Interpretative Phenomenological Analysis (IPA) of the Experience of Parents. J. Genet. Couns. 2018, 27, 1074-1086. [CrossRef] [PubMed]

16. Fidika, A.; Salewski, C.; Goldbeck, L. Quality of Life among Parents of Children with Phenylketonuria (PKU). Health Qual. Life Outcomes 2013, 11, 54. [CrossRef] [PubMed]

17. Gunduz, M.; Arslan, N.; Unal, O.; Cakar, S.; Kuyum, P.; Bulbul, S.F. Depression and Anxiety among Parents of Phenylketonuria Children. Neurosciences (Riyadh) 2015, 20,350-356. [CrossRef]

18. Morawska, A.; Mitchell, A.E.; Etel, E.; Kirby, G.; McGill, J.; Coman, D.; Inwood, A. Psychosocial Functioning in Children with Phenylketonuria: Relationships between Quality of Life and Parenting Indicators. Child. Care Health Dev. 2020, 46, 56-65. [CrossRef] [PubMed]

19. Holmes, E.A.; O'Connor, R.C.; Perry, V.H.; Tracey, I.; Wessely, S.; Arseneault, L.; Ballard, C.; Christensen, H.; Cohen Silver, R.; Everall, I.; et al. Multidisciplinary Research Priorities for the COVID-19 Pandemic: A Call for Action for Mental Health Science. Lancet Psychiatry 2020, 7, 547-560. [CrossRef]

20. Shalev, D.; Shapiro, P.A. Epidemic Psychiatry: The Opportunities and Challenges of COVID-19. Gen. Hosp. Psychiatry 2020, 64, 68-71. [CrossRef] [PubMed]

21. Gualano, M.R.; Lo Moro, G.; Voglino, G.; Bert, F.; Siliquini, R. Effects of Covid-19 Lockdown on Mental Health and Sleep Disturbances in Italy. Int. J. Environ. Res. Public Health 2020, 17, 4779. [CrossRef]

22. Bartoszek, A.; Walkowiak, D.; Bartoszek, A.; Kardas, G. Mental Well-Being (Depression, Loneliness, Insomnia, Daily Life Fatigue) during COVID-19 Related Home-Confinement-A Study from Poland. Int. J. Environ. Res. Public Health 2020, 17, 7417. [CrossRef]

23. Duay, M.; Morgiève, M.; Niculita-Hirzel, H. Sudden Changes and Their Associations with Quality of Life during COVID-19 Lockdown: A Cross-Sectional Study in the French-Speaking Part of Switzerland. Int. J. Environ. Res. Public Health 2021, 18, 4888. [CrossRef]

24. Ventura, P.S.; Ortigoza, A.F.; Castillo, Y.; Bosch, Z.; Casals, S.; Girbau, C.; Siurana, J.M.; Arce, A.; Torres, M.; Herrero, F.J. Children's Health Habits and COVID-19 Lockdown in Catalonia: Implications for Obesity and Non-Communicable Diseases. Nutrients 2021, 13, 1657. [CrossRef] [PubMed]

25. Bascuñán, K.A.; Rodríguez, J.M.; Osben, C.; Fernández, A.; Sepúlveda, C.; Araya, M. Pandemic Effects and Gluten-Free Diet: An Adherence and Mental Health Problem. Nutrients 2021, 13, 1822. [CrossRef] [PubMed]

26. Álvarez Román, M.T.; Butta Coll, N.; García Barcenilla, S.; Pérez González, L.; de la Plaza Collazo, I.; De la Corte Rodríguez, H.; Romero Garrido, J.A.; Martín Salces, M.; Rivas Pollmar, M.I.; Cebanu, T.; et al. Registry of Patients with Congenital Bleeding Disorders and COVID-19 in Madrid. Haemophilia 2020, 26, 773-778. [CrossRef]

27. Riccio, E.; Pieroni, M.; Limoneglli, G.; Pisani, A. Impact of COVID-19 Pandemic on Patients with Fabry Disease: An Italian Experience. Mol. Genet. Metab. 2020. [CrossRef]

28. Pınar Senkalfa, B.; Sismanlar Eyuboglu, T.; Aslan, A.T.; Ramaslı Gursoy, T.; Soysal, A.S.; Yapar, D.; İlhan, M.N. Effect of the COVID-19 Pandemic on Anxiety among Children with Cystic Fibrosis and Their Mothers. Pediatr. Pulmonol. 2020, 55, $2128-2134$. [CrossRef]

29. Havermans, T.; Houben, J.; Vermeulen, F.; Boon, M.; Proesmans, M.; Lorent, N.; de Soir, E.; Vos, R.; Dupont, L. The Impact of the COVID-19 Pandemic on the Emotional Well-Being and Home Treatment of Belgian Patients with Cystic Fibrosis, Including Transplanted Patients and Paediatric Patients. J. Cyst. Fibros. 2020. [CrossRef] 
30. Walkowiak, D.; Bukowska-Posadzy, A.; Kałużny, Ł.; Ołtarzewski, M.; Staszewski, R.; Musielak, M.; Walkowiak, J. Therapy Compliance in Children with Phenylketonuria Younger than 5 Years: A Cohort Study. Adv. Clin. Exp. Med. 2019, 28, 1385-1391. [CrossRef]

31. Vilendrer, S.; Patel, B.; Chadwick, W.; Hwa, M.; Asch, S.; Pageler, N.; Ramdeo, R.; Saliba-Gustafsson, E.A.; Strong, P.; Sharp, C. Rapid Deployment of Inpatient Telemedicine In Response to COVID-19 Across Three Health Systems. J. Am. Med. Inform. Assoc. 2020, 27, 1102-1109. [CrossRef]

32. Barney, A.; Buckelew, S.; Mesheriakova, V.; Raymond-Flesch, M. The COVID-19 Pandemic and Rapid Implementation of Adolescent and Young Adult Telemedicine: Challenges and Opportunities for Innovation. J. Adolesc Health 2020, 67, 164-171. [CrossRef]

33. Wosik, J.; Fudim, M.; Cameron, B.; Gellad, Z.F.; Cho, A.; Phinney, D.; Curtis, S.; Roman, M.; Poon, E.G.; Ferranti, J.; et al. Telehealth Transformation: COVID-19 and the Rise of Virtual Care. J. Am. Med. Inform. Assoc. 2020, 27, 957-962. [CrossRef]

34. Cialone, J.; Augustine, E.F.; Newhouse, N.; Vierhile, A.; Marshall, F.J.; Mink, J.W. Quantitative Telemedicine Ratings in Batten Disease. Neurology 2011, 77, 1808-1811. [CrossRef] [PubMed]

35. Walsh, J.; Markus, H.S. Telemedicine for Follow-Up of Rare Neurological Disease. Stroke 2019, 50, 750-753. [CrossRef]

36. Burke, B.L.; Hall, R.W. Telemedicine: Pediatric Applications. Pediatrics 2015, 136, e293-e308. [CrossRef] [PubMed]

37. McLean, S.; Protti, D.; Sheikh, A. Telehealthcare for Long Term Conditions. BMJ 2011, 342, d120. [CrossRef]

38. Bashshur, R.L.; Shannon, G.W.; Smith, B.R.; Alverson, D.C.; Antoniotti, N.; Barsan, W.G.; Bashshur, N.; Brown, E.M.; Coye, M.J.; Doarn, C.R.; et al. The Empirical Foundations of Telemedicine Interventions for Chronic Disease Management. Telemed J. e-Health 2014, 20, 769-800. [CrossRef]

39. Digital Economy and Society in the EU-Online Shoppers \& e-Purchases. Available online: http://ec.europa.eu/eurostat/cache/ infographs/ict/bloc-2a.html (accessed on 28 March 2021).

40. Davies, W. Insights into Rare Diseases from Social Media Surveys. Orphanet. J. Rare Dis. 2016, 11, 151. [CrossRef] [PubMed] 